\section{Original Research}

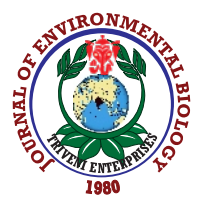

DOI : http://doi.org/10.22438/jeb/4(SI)/MS_1918
Journal Home page : www.jeb.co.in « E-mail : editor@jeb.co.in

\title{
Edible frog species of Nagaland
}

\author{
S. Talukdar' and S. Sengupta ${ }^{2}$ \\ Department of Zoology, St. John College, Dimapur-797 112, India \\ 2Department of Zoology, Assam Don Bosco University, Guwahati -782 402, India \\ *Corresponding Author Email : saibal.sengupta@dbuniversity.ac.in
}

\begin{abstract}
Aim: To identify edible frogs, to evaluate the trade of frog species of Nagaland and to document claimed medicinal value of frogs

Methods: Survey was conducted in eight different markets of Nagaland to record the species of frogs, which were identified following the standard keys. Interviews were conducted among the different age groups to note the uses of frogs and also their medicinal uses.

Results: Thirteen frog species belonging to four different families were recorded in the market survey. The most abundant species was Minervarya teraiensis. Newly discovered species, Megophrys flavipunctata was also found in the market along Euphlyctis ghoshi. Few undiscovered species of Amolops is suspected to be in the diet of Naga people. Regularly, 5-7 species ranging from 150-400 numbers were found in the market. The price varied from INR 150-300 for 3-10 frogs. Popular belief is the consumption of frog hastens skin and bone healing.
\end{abstract}

Interpretation: Collection from the wild may wipe out certain extremely rare endemic species and farming of frog may be an alternative conservation measure.

Keywords: Amolops, Edible frogs, Megophrys, Minervarya, Nagaland, Rhacophorus

\section{Abstract}

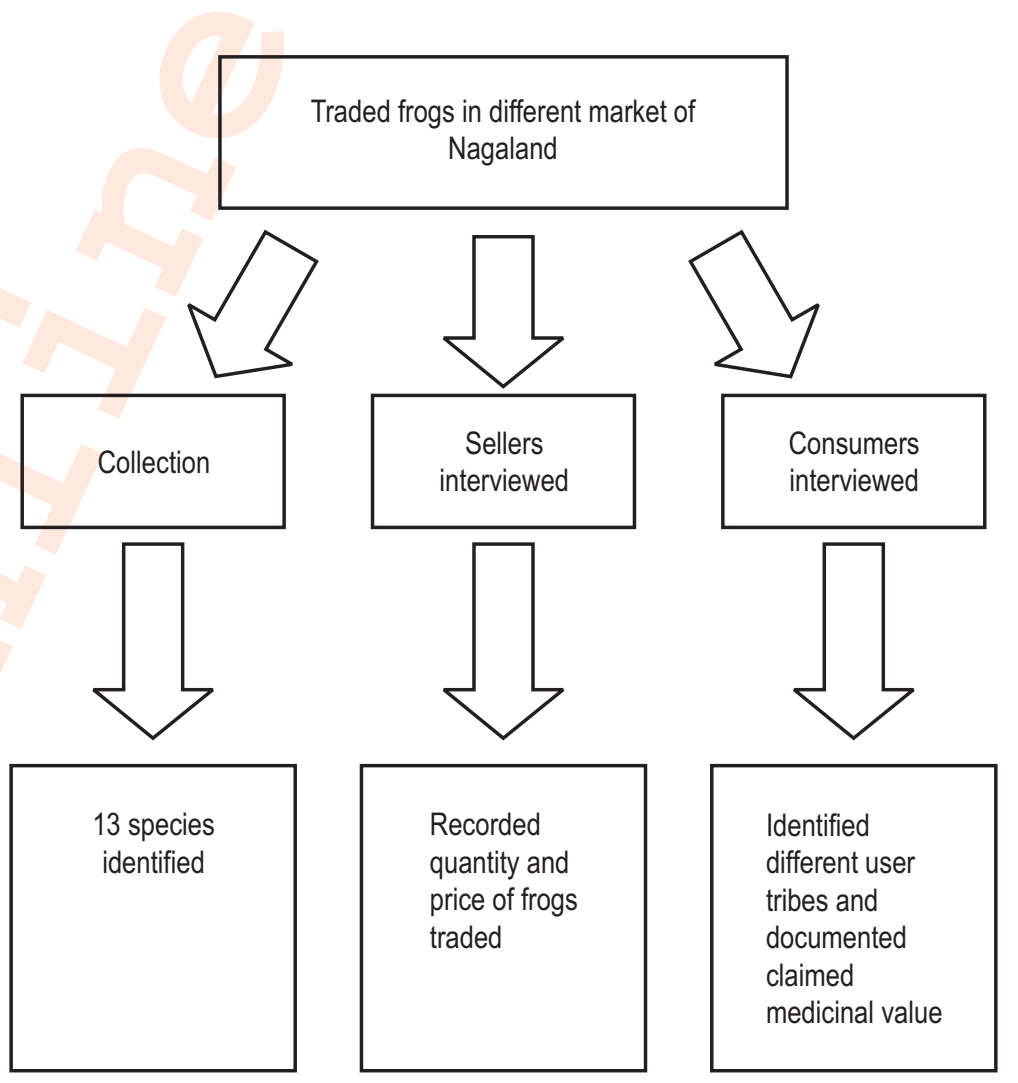

How to cite : Talukdar, S. and S. Sengupta: Edible frog species of Nagaland. J. Environ. Biol., 41, 927-930 (2020). 


\section{Introduction}

Nagaland state of Northeast India (coordinates- $25^{\circ} 15^{\prime}-$ $27^{\circ} 04^{\prime} \mathrm{N}$ latitude and $93^{\circ} 20^{\prime}-95^{\circ} 15^{\prime} \mathrm{E}$ longitude; altitude: 110 $3830 \mathrm{~m}$ above $\mathrm{msl}$ ) is hilly with deep gorges and narrow valleys. The climate, topography and varied ecosystems of the state are conducive for a highly diversified fauna, specifically the amphibians. So far 50 species of amphibians (48 anurans and two caecilians) have been recorded from Nagaland (Ao et al., 2003; Mathew and Sen, 2010; Kamei et al., 2009, 2013; Mahony et al., 2018) of which ten species are endemic to the north eastern region (Saikia and Kharkongor, 2016).

Naga people are known for consuming different animals from insects to large mammals. Live animals like frogs, birds, insects etc., are supplied from outside the state to the local market. It is feared that some species having huge scientific value may end up in dishes of delicacy. Despite having a species-rich amphibian fauna and their presence in diets of people, little is known about the frogs that are in the cuisine of people of Nagaland. In view of the above the present study was conducted to get information of edible frog species and evaluate the trade of frog species in the market of Nagaland.

\section{Materials and Methods}

The study was conducted in all districts of Nagaland. The markets in all districts were surveyed twice in a month from November 2018 to October 2019. The quantity of frogs sold and their prices were recorded. Frog samples were procured from the market for measuring snout-vent length (SVL). Frog species were identified following Boulenger (1920), Chanda (1994), Biju et al., (2010), Mahony et al. (2018). Further, personal interviews were conducted among different age groups. All together 120 individuals were interviewed and the respondents were followed different occupations and belonged to different Naga tribes. The questionnaires were set up in nagamese language to avoid communication problems. All the interviews were conducted in the presence of field assistants speaking nagamese and also other Naga languages. They were enquired about frog species consumed (local name), medicinal use of amphibians in various ailments, and the method of cooking frog meat.

\section{Results and Discussion}

In total 13 frog species belonging to 4 families were sold in different markets (Table 1). During survey, a newly discovered species, Megophrys flavipunctata (Mahony et al., 2018) was recorded in the market. Further, Euphlyctis ghoshi, an extremely rare species of frog, which was not noticed since its discovery in 1990 (Chanda, 1990), was also traded.

The edible frog species recorded during survey are as follows.

Family: Dicroglossidae
Euphlyctis cyanophlyctis (Schneider, 1799): Moderate sized frog (SVL 47-58 mm, HL 14-24mm, SL 7-13 mm); tympanum distinct; tips of fingers and toes pointed, toe webbing complete; dorsal skin granular; dorsum light grey color, sometimes black, with irregular black spots.

Euphlyctis ghoshi (Chanda, 1991): Medium sized frog (SVL 64 $\mathrm{mm} \mathrm{HL} 20 \mathrm{~mm}$ and SL $9.15 \mathrm{~mm}$ ), snout rounded, nostril closer to eyes than snout; tip of fingers and toes blunt, toe webbing complete; dorsal skin granular with irregular tubercle on anterior dorsum, ventral surface smooth ;dorsal brownish with irregular blotches; lateral side variegated; hind limb with incomplete bar.

Minervarya teraiensis (Dubosis, 1984): Medium sized frog (SVL $50 \mathrm{~mm}$ ); head pointed; tip of fingers and toes pointed, both inner and outer metatarsal tubercles present; a distinct skin fringe on the outer side of 5 th toe. Toe web formula was $I_{0-1} I I_{0-1} I I I_{1 / 2-1 / 2} I V_{1 / 2-2}$ $\mathrm{V}$. Pineal organ present as a small dot; dorsal skin with fine glandular fold; dorsum frequently had red or green patches. Males had typical W-shaped dark marking on throat.

Hoplobatrachus crassus (Jerdon, 1854): Large sized frog (SVL 88-95 mm), snout pointed, tympanum distinct; tip of fingers and toes pointed, Inner metatarsal tubercle large shovel shaped, toe webbing complete; dorsum brownish with dark brown to black spots, mid-dorsal line absent; dorsal skin with long pleat like glandular folds, tip of fingers and toes pointed.

Hoplobatrachus tigerinus (Daudin, 1802): Large sized frog (SVL 90-140 mm); snout pointed, tympanum distinct; tip of fingers and toes pointed, Inner metatarsal tubercle digit shaped, toe webbing complete; dorsum yellowish green with longitudinal glandular folds black band from anterior corner of eye through nostrils to anterior edge of upper jaw, fade and irregular band along the lateral margin of upper jaw.

Hoplobatrachus litoralis (Hasan et al., 2012) Large sized (SVL 83 - $91.2 \mathrm{~mm}$ ) frog. Head slightly broader, snout pointed, tympanum distinct; tip of fingers and toes pointed, inner metatarsal tubercle digit shaped, toe webbing complete; dorsum brownish with longitudinal glandular folds; a distinct broad black band from anterior corner of eye through nostrils to anterior edge of upper jaw, and another band along the lateral margin of upper jaw, a distinct black margin on inner side of the upper arm.

\section{Family-Megophryidae}

Megophrys major (Boulenger, 1908): Large sized frog (SVL 68$75 \mathrm{~mm}$ ). Head broad, triangular, nostril closer to eyes, tympanum distinct, dorsal skin smooth with fine folding and small tubercles, tip of fingers and toes rounded, rudimentary webs, a dark brown triangular patch between eyes, a thin hour glass mark on the back.

Megophrys flavipunctata (Mahony et al., 2018): Large sized 
Table 1 : Different species of edible frogs with their IUCN and market status

\begin{tabular}{|c|c|c|c|}
\hline Family & Species & IUCN status & Availability in market \\
\hline \multirow[t]{6}{*}{ Dicroglossidae (6) } & Euphlyctis cyanophlyctis & LC & Abundant \\
\hline & Euphlyctis ghoshi* & $\mathrm{DD}$ & Extremely rare \\
\hline & Fejervarya teraiensis & LC & Abundant \\
\hline & Hoplobatrachus crassus & LC & Infrequent \\
\hline & Hoplobatrachus tigerinus & LC & Common \\
\hline & Hoplobatrachus litoralis & NE & Infrequent \\
\hline \multirow[t]{2}{*}{ Megophryidae (2) } & Megophrys major & LC & Infrequent \\
\hline & Megophrys flavipunctata* & $\mathrm{NE}$ & Rare \\
\hline \multirow{2}{*}{ Ranidae (2) } & Amolops marmoratus & NA & Common \\
\hline & Pterorana khare & LC & Extremely rare \\
\hline \multirow[t]{3}{*}{ Rhacophoridae (3) } & Polypedates teraiensis & LC & Infrequent \\
\hline & Rhacophorus bipunctatus & LC & Infrequent \\
\hline & Rhacophorus maximus & LC & Infrequent \\
\hline
\end{tabular}

- Endemic to Northeast India

frog (SVL $59 \mathrm{~mm}$ ), Head broader than long, snout bluntly pointed, without rostral appendage, nostril positioned, closer to eye than to snout; toes long, dorsoventrally flattened, with narrow lateral fringe, basal webbing between toes; creamy upper lip stripe, two dark brown blotches on anterior lateral surface of forearms.

Family-Ranidae

Amolops marmoratus (Blyth, 1855): Large sized frog (SVL 57$76 \mathrm{~mm}$ ); head slightly broader than long; Nostril closed to tip of the snout than to eye; Tympanum oval; tip of fingers and toes dilated into large adhesive spade like pad; full toe webbing; Dorsal skin granulated, green to brown and marble with dark brown or grey spots.

Pterorana khare (Kiyasetuo and Khare, 1986): Moderate sized frog (SVL $60 \mathrm{~mm}$ ); body elongated; nostril equidistant from eye and nostril; tip of fingers and toes dilated; toe webbing complete; lateral skin folded between back of the tympanum to thigh; webbing complete.

\section{Family-Rhacophoridae}

Polypedates teraiensis (Dubosis, 1987): Moderate sized frog (SVL 55-85 mm); head longer than broad, nostril closer to tip of the snout than eyes; tympanum distinct; fingers with rudimentary web and well developed discs; tip of toes dilated into well developed discs, toes two - third webbed. Dorsum yellowish to grey with three to four longitudinal bands extending from snout to vent. Limbs with dark cross bandss; Ventral surface white; Skin on head ossified

Rhacophorus bipunctatus (Ahl, 1927): Medium sized frog (SVL 37-59 mm); Head broad, position of nostril almost equidistant from eye and tip of the snout; Fingers and toes with terminal disc; Dorsum slate green and ventrum bright yellow. Characteristic black spot prominent on flanks.
Rhacophorus maximus (Günther, 1858): Large sized stoutbuilt frog (SVL $102.75 \mathrm{~mm}$ ). Head broad, nostril equidistant from eye and snout tip, tympanum distinct; Fingers and toes fully webbed; Dorsum slate green or dark green, ventral surface light yellow.

Kiyasetuo (1986) while discussing the edible frogs of Nagaland recorded 12 species belonging to four families. However, species reported, like Rana verrucosa (synonym of Minervarya keralensis) is a Western Ghats endemic (Biju et al., 2016, Frost, 2020), Rana nagalandsis is an invalid name, and Rhacophorus nigropalmatus, which does not have distribution range in India (Frost, 2020), are probably misidentified. Further, Kiyasaetuo (1986) recorded Amolops afghanus, Nanorana liebigii and Hyla annectens as edible frogs of Nagaland, however, in the present study there were not reported in the market. In the present study new records of edible frog from Nagaland include Hoplobatrachus litoralis, H. crassus, Euphlyctis ghoshi, Megophrys major, M. flavipunctata, Rhacophorus maximus, $R$. bipunctatus, Pterorana khare and Amolops marmoratus. The presence of two endemic and extremely rare species in the list of edible frog (Table 1) is concern. In the present study two species of Megophrys were reported in the market. Taking into account of both the records it is assumed that at least 18- 20 species of frog are consumed by Naga population. Chetri et al. (2011) opined that frogs are hunted for meat and for medicinal value in Sikkim, but there is no commercial use of frogs. They, however, recorded Megophrys species as most preferred along with Nanorana liebegii and Amolops marmoratus.

In the market, five to seven species of frogs are traded at regular basis. The price varies from species to species and also with size. The medium and large sized 3-10 frogs are sold @ INR 150.00 to 300.00 of frogs. Small sized 5-10 frogs are priced at INR 50.00 - 100.00. Minervarya teraiensis was found to be most common specie in the market followed by Euphlyctis 
cyanophlyctis. Hoplobatrachus tigerinus was also found to be common; however, a sizeable portion of this frog is supplied to the market of Nagaland from the adjacent states. Kiyasetuo (1986) recorded common species like Hoplobatrachus tigerinus, Euphlyctis cyanophlyctis, Minervarya species (reported as Fejervarya limnochariss) and Polypedates teraiensis (reported as Rhacophorus leucomystax) in the market regularly.

Kiyasetuo (1986) reported seven tribes, namely Angami, Ao, Sema, Lotha, Rengma, Chakhesang and Zeliang, that consumed frogs for various medicinal purposes. Further, $100 \%$ of the interviewed populations were aware that frog's meat is a great source of protein for human. They believed that the frog meet have medicinal importance and consuming frog in different ways can cure many ailments. They are of the opinion that frog meat is good for healing fractured bones, excellent for curing burn wounds, and massaging fat of the frog can relieve rheumatic joint pain. Fresh frog meat is believed to have prophylactic action against postoperative infection and also any organ injury. Kiyasetuo (1986) mentioned that swallowing of live frogs for treatment of GI tract infections and using of peeled frog skin for healing burn injuries. The results of the study revealed ethnobatrachological knowledge of the people of Nagaland and traditional utilization of frogs in treatment of various ailments. The findings of the present study may be used in developing modern scientific drugs for the treatment of various diseases. A couple of rare and endemic species are appeared to be threatened due to their open trade in the markets of the state

\section{Acknowledgment}

The authors are thankful to the interviewees for sharing their traditional knowledge, shopkeepers for contributing information on the frogs and students of the Zoology Department, St. John College, Dimapur for helping throughout the study period. We are also grateful to the authority of Assam Don Bosco University for support and encouragement.

\section{References}

AO, J.M., S. Bordoloi and A. Ohler: Amphibian fauna of Nagaland with nineteen new records from the state including five new records for India. Zoo's Print J., 18, 117-125 (2003).

Biju, S.D., S. Mahony and R.G. Kamei: Description of two new species of torrent frog, Amolops cope (Anura: Ranidae) from a degrading forest in the northeast Indian state of Nagaland. Zootaxa, 2408, 31-46 (2010).
Biju, S.D., S.K. Dutta and M.S Ravichandran: Fejervarya keraalensis. The IUCN Red List of Threatened Species 2016:e. T58273A91232746.HTTPS:??DX.DOI.ORG/10.2305/IUCN.UK.2 016-1.RLTS.T58273A91232746.en. (2016).

Boulenger, G.A.: A monograph of the south Asian, Papuan, Malaysian and Australian frogs of the genus Rana. Record Indian Museum, Calcutta, Vol. XX, 1-226 (1920).

Chanda, S.K.: A new frog of the genus Rana (Anura: Ranidae) from Manipur, Northeastern India. Hamadryad, 15, 16-17 (1990).

Chanda, S.K.: Anuran (Amphibia) fauna of Northeast India. Memo. Zool. Surv. India, 18, 141-143 (1994).

Chetri, B., B.K. Acharya and S. Bhupathy: An overview of the herpetofauna of Sikkim with the emphasis on elevational distribution pattern and threats and conservation issues. In: Biodiversity of Sikkim, Exploring and Conserving a Global hotspot (Eds: M.L. Arrawatia and S. Tambe) Information and Public Relation Department, Govt. Sikkim, Gangtok. p. 233 (2011).

Frost, D.R.: Amphibian Species of the World: An Online Reference. Version 6.1 (accessed on 02.02.2020). Electronic database accessible. American Museum of Natural History, New York, USA, doi.org/10.5531/db.vz.0001 (2020).

Hasan, M. K., M. Kuramoto, M. M. Islam, M. S. Alam, M. M. R. Khan, and M. Sumida: A new species of genus Hoplobatrachus (Anura, Dicroglossidae) from the coastal belt of Bangladesh. Zootaxa, 3312, 45-48 (2012).

Kamei, R., D.J. Gower, M. Wilkinson and S.D. Biju: Systematics of the caecilian family Chikilidae (Amphibia: Gymnophiona) with the description of three new species of Chikila from northeast India. Zootaxa, 3666, 401-435 (2013).

Kamei, R., M. Wilkinson, D.J. Gower and S.D. Biju: Three new species of striped Ichthyophis (Amphibia: Gymnophiona: Ichthyophiidae) from the northeast Indian states of Manipur and Nagaland. Zootaxa, 2267, 26-42 (2009).

Kiyasetuo: Edible frogs of Nagaland. Proc. First World Conf. on Trade in Frog legs, Calcutta, 2, 100-103 (1986).

Mahony, S., R.G. Kameim, E.C. Teeling and S.D. Biju: Cryptic diversity within the Megophrys major species group (Amphibia: Megophryidae) of the Asian Horned Frogs: Phylogenetic perspective and a taxonomic revision of South Asian Taxa, with description of four new species. Zootaxa, 4523, 001-096 (2018).

Mathew, R. and N. Sen: Pictorial Guide to the amphibians of North-East India. Director, Zoological Survey of India, Kolkata, India, pp. 141144. (2010).

Saikia, B. and I.J. Kharkongor: Checklist of endemic amphibians of Northeast India. Rec. Zool. Surv. India, 117, 91 -93 (2016).

Terang, N.: Huge consignment of frogs seized in Karbi Anglong on way to Dimapur. https://nenow.in/environment/huge-consignment-offrogs-seized-in-karbi-anglong-on-way-to-dimapur.html (2019).

Walling, I.: http://morungexpress.com/dating-undatables (2017) 